\title{
Protagonismo juvenil e práticas semióticas: exame de algumas propostas da teoria
}

DOI: http://dx.doi.org/10.21165/el.v48i3.2222

\section{Daniel Carmona Leite ${ }^{1}$}

\section{Resumo}

Neste artigo, examinamos algumas das principais propostas teóricas da área da semiótica no que diz respeito às práticas. Realizamos tal empreendimento com vistas a um diálogo teórico com a metodologia educativa do protagonismo juvenil, cuja popularidade aumentou nas últimas décadas no Brasil. Em um primeiro momento, descrevemos a proposta de Fontanille, que depreende diferentes níveis de imanência nas manifestações textuais. Em seguida, dedicamo-nos a observar a teoria de Landowski, cujas formulações visam dar conta de diferentes regimes de interação, integrando à teoria noções como risco e programação. Por fim, recuperamos algumas propostas de Greimas no tocante ao estudo da gestualidade, vendo-as em perspectiva com postulações feitas por Tatit.

Palavras-chave: práticas semióticas; protagonismo juvenil; narratividade, ação; educação.

1 Universidade de São Paulo (USP), São Paulo, São Paulo, Brasil; daniel.leite@usp.br; http://orcid.org/0000-0003-0270-3634 


\title{
Youth protagonism and semiotic practices: an outline of theories done in the field
}

\begin{abstract}
In this article, we examine some of the main theoretical theories in the field of French Semiotics regarding the issue of the practices. We take this path in order to establish a dialogue with the educational methodology of youth protagonism. This concept has been increasingly used in the last decades in Brazil. In a first moment, we analyze the theory of Fontanille, whose model has different levels of immanent textual manifestations. After that, we dedicate to describe the work of Landowski. This author's ideas aim to offer a semiotic construct that is capable of dealing with different interaction regimes. In the end, we recover a few propositions by Greimas about gestures and put these ideas in perspective with some reflections on this issue made by Tatit.
\end{abstract}

Keywords: semiotic practices; youth protagonism; narrativity; action; education.

\section{Introdução}

“Protagonismo" é um termo do português cuja origem remonta à Grécia Antiga. Trata-se de palavra formada pela composição dos radicais protos- (que, resumidamente, significa o primeiro, o principal; BAILLY, 1935; HOUAISS; VILLAR, 2007) e agonistes (também em linhas gerais, lutador ou atleta, competidor; BAILLY, 1935; HOUAISS; VILLAR, 2007). A popularidade de seu uso aumentou muito nas últimas décadas no Brasil, chegando a ganhar algo como uma "esfera própria de sentido" e a ser aplicada a cenários e contextos discursivos específicos. Costa (2000) constata a proliferação da ideia de "protagonismo juvenil", em especial no que diz respeito a algumas práticas de formação de jovens do âmbito nacional, nas últimas décadas. Em sua obra, postula-se uma metodologia de ação educativa baseada nesse princípio.

Para comprovar a difusão desse ideal também em nível internacional, basta percorrer rapidamente a obra Educação: um tesouro a descobrir: Relatório para a UNESCO da Comissão Internacional sobre Educação para o século XXI. Nela, encontram-se reflexões como as do economista e político francês Jacques Delors que elenca, dentre as tensões a se superar no âmbito das práticas educativas para o século, a necessidade de uma integração das culturas locais na realidade global "sem perder suas raízes pela participação ativa na vida do seu país e das comunidades de base" (DELORS et al., 2010, p. 8, grifos nossos). O traço agentivo mencionado recupera a ideia de que, para uma renovação do panorama citado, é necessário que os "atores sociais" dessa transformação estejam próximos e atuantes na vida das localidades às quais pertencem. Visto isso, o protagonismo não exige muito esforço para ser reconhecido como um item importante da agenda mundial contemporânea. 
Neste artigo, caminhamos em direção ao mapeamento de algumas das abordagens feitas das problemáticas das práticas, da ação e da gestualidade na área da semiótica de linha francesa. Temos o objetivo de aproximar, interdisciplinarmente, essas ideias à metodologia educativa idealizada por Costa $(2000,2007)$, visando uma aplicação futura das reflexões deste estudo para a análise de relatos autobiográficos de jovens brasileiros, coletados especialmente para a tese de doutorado que estamos realizando atualmente e da qual o presente artigo é derivado.

Antônio Carlos Gomes da Costa (educador, dirigente técnico e autor) é autor do livro Protagonismo juvenil: adolescência, educação e participação democrática (2000), uma das referências na área sobre o tema no Brasil. Tendo escrito e atuado no atendimento, promoção e defesa dos direitos da população infantojuvenil, define "protagonismo" com as seguintes palavras: "O termo 'protagonismo', em seu sentido atual, indica o ator principal, ou seja, o agente de uma ação, seja ele um jovem ou um adulto, um ente da sociedade civil ou do Estado, uma pessoa, um grupo, uma instituição ou um movimento social." (COSTA, 2000, p. 20, grifos nossos).

Em primeiro lugar, vemos que tal definição, ao utilizar a expressão "ator principal", confere a um destinador-julgador narrativo - discursivamente implícito - o papel de sancionar positivamente ou de conferir destaque ao destinatário-julgado. Este último actante estaria manifestado textualmente, no caso, pela figura do ator que é considerado protagonista pelo enunciador. Quando observamos o uso da expressão "o agente de uma ação", ainda da definição acima, há, no contexto da frase, a adoção de um posicionamento. O uso do artigo definido "o" mostra que, dentre várias ações possíveis, é apenas um curso prático que goza de destaque no "modo de ver" daquele que assume a voz do texto. Assim, é a escolha tomada por esse actante da enunciação que desempenha um papel decisivo na determinação daquele ator que é considerado importante para a perspectiva tomada. A partir dessa reflexão, podemos afirmar que a instauração do protagonismo segundo essa visão - assim como o ato de conferir destaque a um fazer qualquer por meio de um discurso - pode ser também uma forma de atribuição de poder.

Quando a escolha que determina quem é o protagonista de um texto dado diz respeito a uma apreciação feita por um ator concomitante com o do fazer (como poderia acontecer no caso de um texto autobiográfico), estaríamos diante de algo que propomos aqui denominar sanção reflexiva. Nesse caso, haveria um sincretismo atorial que reuniria os actantes destinador-julgador e destinatário-julgado em apenas uma instância discursiva. De maneira correlata, quando não houvesse essa superposição de papéis em uma mesma figura, teríamos sanção transitiva, uma vez que ocorreria, aí, uma atribuição de juízos feita por um ator visando a caracterização de outro.

O principal objetivo de se estudar e de se incentivar a prática do protagonismo juvenil é, segundo Costa (2000, p. 21), promover "a formação integral do educando, a sua 
preparação para a cidadania e sua qualificação para o trabalho". O autor alega que a difusão dessa metodologia tem rendido bons frutos na área, utilizando-a como estratégia para propiciar o desenvolvimento pessoal dos adolescentes, assim como o "desenvolvimento de qualidades que os capacitam para ingressar, permanecer e ascender no mundo do trabalho" (COSTA, 2000, p. 21). Estando relacionadas a transformações tais como a "formação integral do educando" ou seu desenvolvimento enquanto indivíduo, as ações feitas nesse sentido dialogam com a capacidade reflexiva das pessoas de atribuir valor às próprias realizações em âmbitos variados, tanto quando estamos falando de um viés prospectivo, que estipula os objetivos a serem alcançados, quanto ao nos depararmos com uma perspectiva retrospectiva, que avalia o que já foi feito.

Tendo examinado brevemente algumas acepções de protagonismo e as construções semióticas subjacentes a elas, passemos ao exame das práticas no campo citado, o que nos interessa mais neste artigo. A partir das reflexões realizadas nesse sentido, esperamos obter melhores condições para analisar textos orais autobiográficos com base nas diferentes formas de ação que neles se encontrem presentes.

\section{As práticas em diferentes correntes da semiótica}

Se nossas ações são permeadas pelos discursos que lhes conferem sentido, os projetos de atividade elaborados pelas pessoas são componentes essenciais do fazer humano. Essas formas de planejamento práxico podem se dar em um nível social, como nos fazeres culturalmente significativos, assim como individualmente, no caso da motivação pessoal. Podem ser fruto de uma reflexão consciente por parte do sujeito, mas por vezes não implicam uma reflexão premeditada. De todo modo, na análise das práticas, é difícil conceber a existência de um ator completamente desinteressado ou desimplicado em seu fazer. Fontanille (2008, p. 130, tradução nossa²) reconhecia isso, como se vê na citação a seguir. "[...] toda prática possui uma parcela de interpretação e toda interpretação é, essencialmente, uma prática e a partir disso podemos concluir que toda prática comporta, ao menos em potência, uma dimensão estratégica".

Independentemente de aderir completamente à proposta teórica da obra citada, que prevê a existência de uma organização hierárquica de planos de imanência em cada texto a ser analisado, podemos reconhecer e nos valer da reflexão do pesquisador para o raciocínio que aqui desenvolvemos. A dimensão estratégica mencionada, associada à interpretação, evoca a ideia de que as ações devem possuir mais de um nível de existência para adquirir sentido. Poderíamos ter, assim, a relativização da importância de projetos locais diante de planejamentos mais significativos e globais, noção à qual retornaremos mais adiante.

2 No original: "[...] toute pratique comprend une part d'interprétation et toute interprétation est elle-même une pratique, et il en résulte que toute pratique comporte au moins potentiellement une dimension stratégique intégrée". 
Landowski (2014) também irá problematizar a afirmação acima, postulando a existência dos diferentes regimes de interação. Percorreremos esse segundo assunto com mais detalhe no item 2.2.

É possível reconhecer diferentes formas de determinação dos valores que regem as ações de um indivíduo ou de uma coletividade. Um legado familiar ou tribal, por exemplo, atribui sentido às práticas de um ator a partir de uma ascendência dada; assim como determinados grupos sociais (religiosos, profissionais etc.) também podem fazê-lo. Entendemos que os processos de significação - e as pesquisas elaboradas a partir deles - são de grande valia no estudo dessa complexa problemática. O traço aspectual da duratividade, por exemplo, encontra-se presente em planejamentos de ordem individual, como no hábito e na rotina. Já no momento em que se trata de fazeres coletivamente instituídos (ações típicas de comunidades ou de sociedades inteiras), teríamos, sob o mesmo traço, o que seriam os costumes ou as tradições.

\subsection{Práticas semióticas em Fontanille}

Fontanille (2008) traz uma abordagem teórica que busca integrar os diferentes mecanismos e construções das práticas, entendendo-os como situações semióticas. Para realizar essa tarefa, faz uso de um modelo teórico que destrincha as diferentes etapas constituintes da significação, integrando-as em um percurso mais amplo que daria conta das diferentes estratificações de sentido identificadas nos textos. O nível das práticas é entendido como o momento do processo no qual ocorreria o investimento das propriedades dêiticas. Estas envolveriam um espaço tridimensional (onde existiria profundidade) e uma temporalidade dotada de perspectiva, uma vez que ela estaria, nesse contexto, relacionada a um corpo de referência. Nesse sentido, argumenta o autor, "há, portanto, boas razões para se falar, nesse caso, da dimensão 'topo-cronológica' da cena predicativa ${ }^{3 \prime}$ (FONTANILLE, 2008, p. 57, tradução nossa, grifos do autor). Esse mesmo nível das práticas seria, ainda segundo ele, também o locus da aspectualização e dos investimentos rítmicos, a partir dos quais as estruturas independentes do texto e do objeto receberiam, localizariam e modalizariam as interações entre os parceiros das práticas .

As práticas semióticas, para Fontanille (2008), encontram-se situadas entre outros dois níveis, o da corporeidade (menos elaborado do que o primeiro) e o da conjuntura (mais complexo do que ele). Todos esses estratos estão situados em um percurso gerativo de planos de imanência, cujo funcionamento obedece a uma lógica de conversão que vai se tornando mais complexa gradualmente, a exemplo do que ocorre com os níveis de significação depreendidos pela semiótica greimasiana clássica (profundo, narrativo

3 No original: "on peut alors à juste titre parler ici de la dimension 'topo-chronologique' de la scène prédicative". 
e discursivo). O autor utiliza a expressão instâncias formais para designar os elementos pertinentes ao plano dentro do qual estão inseridos. No quadro elaborado originalmente pelo pesquisador, as práticas ocupam o quarto tipo de experiência no modelo, de cima para baixo. A tradução dos termos originais ao português que utilizamos foi obtida de Silva e Portela (In: PORTELA et al., 2012).

A instância formal-estrutural do nível das práticas é a cena predicativa, que faz interface com a morfologia práxica (corporeidade). Quando vista como instância do estrato próprio, porém, essa cena é concebida, por sua vez, como um processo de acomodação integrado no nível subsequente, conjuntura, com a gestão estratégica das práticas. Essa movimentação decorre do procedimento de conversão e composição próprio da proposta. O funcionamento do esquema prevê que, desde o primeiro nível de experiência (figuratividade), todas as propriedades materiais estariam já presentes, constituindo o que o autor denomina a matéria da expressão (FONTANILLE, 2008). Assim, a progressiva elaboração do tipo de experiência engendraria a série de planos de imanência sucessivos e permitiria descrever, com mais riqueza de elementos, os traços constitutivos dos fenômenos de linguagem.

Fontanille (2008) situa as práticas em meio a um percurso hierárquico e procura dar conta de aspectos da significação que estavam anteriormente fora do escopo analítico. Se, inicialmente, a semiótica excluía o contexto de suas análises, o esforço desse pesquisador se dá, entre outras funções, no sentido de sanar essa deficiência. Vejamos, em seguida, algumas palavras do autor que procuram justificar a inserção desse novo dispositivo na teoria.

Propor uma semiótica das práticas não consiste, portanto, em colocar um objeto de análise qualquer em seu contexto, mas, ao contrário, a integrar o contexto no objeto a se analisar, aproveitando todas as consequências do fato de que, semioticamente falando, o contexto não se situa "nem a montante, nem a jusante, mas no coração da linguagem ${ }^{4 \prime}$. (FONTANILLE, 2008, p. 14, tradução nossa).

A citação entre aspas no fim do trecho transcrito vem de Landowski (La societé réfléchie). Em nossa opinião, o dispositivo de Fontanille (2008) para a descrição das práticas semióticas ainda não teve tempo de aplicação o suficiente para comprovar sua efetiva pertinência no que é o instrumental teórico da área. Se, por um lado, é louvável a sistematização que propõe, por outro, ainda escapa à nossa compreensão a efetiva sustentação da proposta no quadro teórico da semiótica a longo prazo. De todo modo,

4 No original, "Proposer une sémiotique des pratiques ne consiste donc pas à plonger un objet d'analyse quelconque dans son contexte, mais au contraire à intégrer le contexte dans l'objet à analyser, en tirant toutes les conséquences du fait que, sémiotiquement parlant, le contexte ne se situe 'ni en amont ni en aval, mais au cœur du langage'". 
tal autor não é o único dos seguidores de Greimas que trata do universo das práticas e de suas significações. Sigamos com nosso exame panorâmico do assunto indo à abordagem de outro pesquisador francês.

\subsection{Regimes de interação - a função do risco na significação}

Landowski (2014) revê as estruturas de base que regem algumas das interações semióticas e, com perspicácia, propõe uma classificação com quatro principais regimes que supostamente a governariam, a saber, a programação, o acaso (ou acidente), o ajustamento e a manipulação. Esses diferentes tipos de interação estariam inseridos dentro de uma lógica de aumento e diminuição do risco, princípio entendido pelo autor como um dos elementos centrais do sentido. O regime que mencionamos primeiro (a programação) seria aquele que estaria mais livre de risco ao passo que o acaso seria o mais sujeito a esse tipo de influência. Outra conquista importante dessa proposta, a nosso ver, é a incorporação de uma lógica gradual de transição entre os diferentes modos propostos. Isso fornece recursos para descrições processuais das passagens de um regime a outro, como bem constata Fiorin, no prefácio à edição brasileira da obra (LANDOWSKI, 2014).

Landowski (2014) formula críticas ao modelo semiótico greimasiano de descrição da manipulação narrativa, argumentando que havia uma falta de profundidade do tratamento teórico dado a esse tipo de interação. Algumas das palavras que manifestam essa problematização estão expressas no trecho a seguir.

No atual estado da teoria, tudo se passa como se, uma vez excluído o puro e simples recurso à força, que levaria a reduzir o outro ao estatuto de coisa programada, a única maneira de influenciá-lo - de ter prise sobre ele - consistisse em concebê-lo como um ser consciente de si mesmo [...] (LANDOWSKI, 2014, p. 49, grifos do autor).

Estamos de acordo com Landowski (2014) quanto ao que é afirmado acima. Vemos que havia, nas primeiras abordagens da semiótica para a descrição do destinadormanipulador, por exemplo, uma tendência a tomá-lo como um actante dotado de plena intencionalidade objetiva. A nosso ver, a distinção entre transitividade (fazer ser) e factitividade (fazer fazer), reconhecida por Greimas (2014), ganha sofisticação quando revista pela pena de Landowski (2014). O esquema a seguir representa uma formulação visual, feita por nós, da proposta do último autor. Para fins de foco, ocultamos da figura as categorias da continuidade e descontinuidade, suas respectivas negações e outras informações constantes na proposta original. Nossa intenção em fazê-lo não foi a de propor qualquer reformulação no escopo da teoria. Apenas procuramos, com essa apresentação simplificada, prover uma imagem mais apta a atender a finalidade argumentativa que nos interessa no momento. 


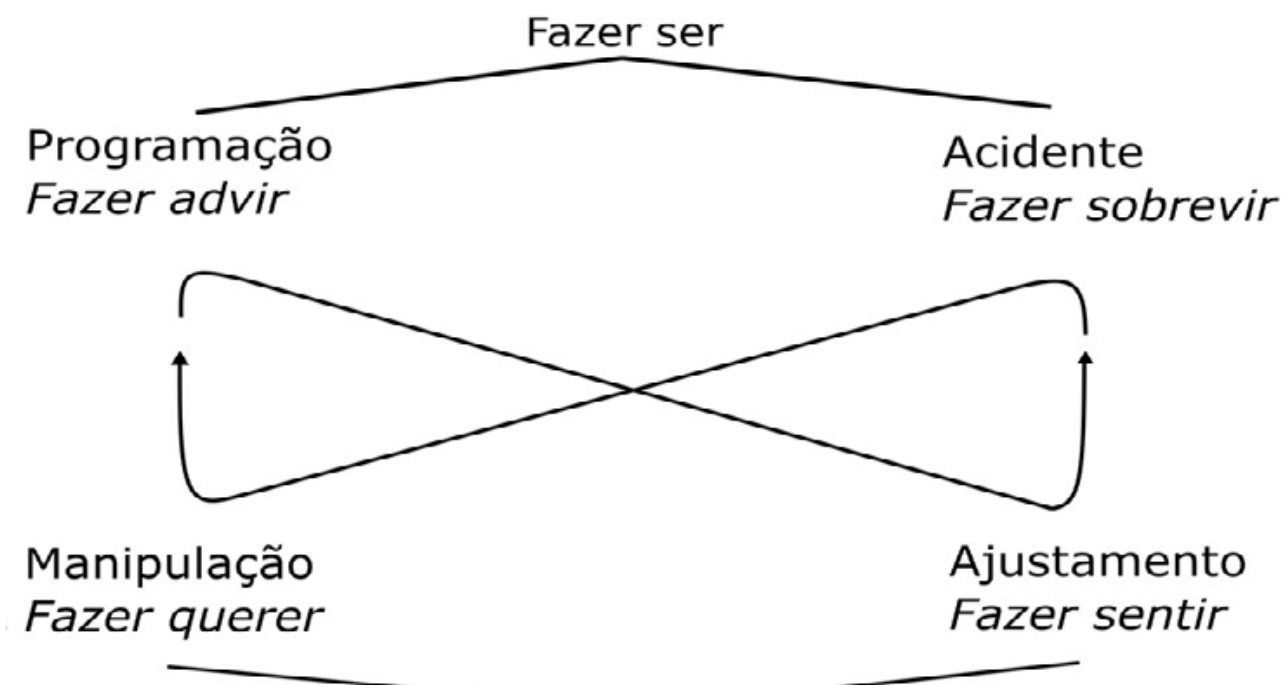

Fazer fazer

Figura 1. Diagrama dos regimes e tipos de interação

Fonte: Elaboração própria, adaptado de Landowski (2014, p. 80).

A imagem acima mostra, de maneira aproximada, o modo pelo qual o autor francês desdobra as categorias de Greimas em dois pares de eixos, um situado no alto do esquema (eixo da transitividade ou da operação, fazer ser), outro no âmbito inferior (eixo da factividade, fazer fazer). O termo manipulação, usualmente entendido pelos semioticistas como sinônimo de factitividade, ou seja, como regente de uma relação de ordem intersubjetiva, nessa proposta, fica identificado com um dos funtivos possíveis de uma relação participativa. Nesta, abarcaria apenas o fazer querer e a não descontinuidade. Vemos tal reformulação com bons olhos, pois ela remove o apelo contraintuitivo que o uso do termo manipulação, em sua antiga função, evocava, como no caso da interação de ordem estésica, por exemplo. No que diz respeito ao ajustamento, lembramos que, para Landowski (2014), este não seria orientado por leis preestabelecidas. Ele aconteceria, ali, no "tempo real" do processo de interação, na maneira com a qual os parceiros de comunicação interagiriam pouco a pouco.

Se, na manipulação, teríamos, implícita, uma busca do sujeito-operador de um programa pressuponente(oriunda da influência pressupostapelafunção de destinador-manipulador), no ajustamento, o que move esse actante é uma inquietude que se aproxima àquela da realização mútua, como no caso dos parceiros de dança (LANDOWSKI, 2014). No caso da guerra, para o autor, uma abordagem de ajustamento seria algo como um incentivo para que o exército oponente avançasse e terminasse por desenvolver propriedades autodestrutivas próprias. 
Além disso, o pesquisador nos lembra, no quadro da tipologia das programações existentes, da existência de programações causais cuja instauração obedeceria a leis de regularidades operacionais e supostamente não motivadas, tais como as razões denominadas físicas, fisiológicas ou biológicas (LANDOWSKI, 2014). Quando os atores de um texto em exame obedecem ao conjunto dos comportamentos humanos (sendo eles antropomorfizados ou não), normalmente não poderíamos deixar de conferir algum sentido (cultural ou individual) a suas ações - por menor que fosse. 0 autor afirma que muitas das regularidades que são tomadas como "puros automatismos anônimos" (LANDOWKSI, 2014, p. 37), na verdade, ocultam o ponto de vista dos agentes envolvidos, o que faz com que seja necessário reconhecer as necessidades de ordem simbólica presentes nos discursos. Examinemos mais uma citação sua, transcrita abaixo, a respeito da manipulação.

Se, para eles [os agentes envolvidos em determinada interação de manipulação], essas condutas são "inquestionáveis", é porque por trás delas há sentido, ainda que o conteúdo não seja, ou não seja mais, diretamente acessível. "Por que esse rito particular? Por que se faz desse modo? - Porque é assim que se faz, porque é assim que se deve fazer". (LANDOWSKI, 2014, p. 38, grifos do autor).

No caso mencionado acima, verificamos a presença de uma necessidade ou motivação que não precisa de explicação racional para se efetivar; trata-se simplesmente de uma crença em um destinador. Para essas situações, Landowski (2014) utiliza a denominação motivação-confiança, algo como um princípio que visaria a reiteração ou a perpetuação de práticas instituídas. Quando estamos diante de atores cujos investimentos figurativos não têm o traço antropomorfo, podemos falar, com menos risco de equívoco, em ações perpetradas sob um regime de interação causal, como, por exemplo, a água que ferve sob a influência do calor da tocha do fogão. Nessas situações, o próprio estatuto subjetivo do operador seria tomado como questionável. Vejamos outra argumentação do autor. [...] a manipulação, pelo simples fato de que põe em relação "sujeitos" isto é, actantes em grande medida habilitados para escolher seus percursos em função de motivações ou de razões ligadas a uma competência modal que nada limita a priori -, oferece um inventário de possibilidades narrativas extremamente aberto. Por outro lado, a programação, que por natureza encerra os protagonistas em configurações semânticas imutáveis (os papéis temáticos encontrados mais acima) determina um registro objetivamente mais reduzido, em todo caso em termos quantitativos. (LANDOWSKI, 2014, p. 65).

Um segundo modo de recção da manipulação é denominado por Landowski (2014) motivação-decisão. Essa forma de interação seria típica de um sujeito capaz de decidir por conta própria ou, em nossos termos, um actante apto a estabelecer um contrato que seria, em certa medida, reflexivo. Tal modo obedeceria a uma aspectualidade pontual 
e incoativa, vista em oposição àquela da motivação-confiança, que seria durativa e contínua. Isso ocorreria porque, para se firmar como regime escolhido pelo sujeito, a primeira precisaria validar seu valor atestado. Ela deveria justificar qualquer abandono das tradições, manias ou superstições, sendo estas últimas antagônicas à causalidade de ordem decisional.

Por fim, o regime de interação do acidente, derradeira categoria a ser comentada por nós, poderia ser sintetizado como um dispositivo guiado pela lógica da aleatoriedade, no qual o princípio do risco encontraria sua manifestação mais essencial. Ele poderia recobrir tanto manifestações decisivas para a vida dos atores (um raio que cai sobre a cabeça de um indivíduo), como fenômenos insignificantes (por exemplo, uma folha que se solta de um galho de uma árvore e bate na perna de alguém). Basicamente, seria uma descontinuidade não controlada. As formas de semantizar um tal regime seriam várias e estariam expressas em palavras como "sorte", "azar" ou mesmo "acaso" (LANDOWSKI, 2014). A lógica do acaso estaria oposta à da necessidade. Ademais, o acidente poderia ser tomado pelo sujeito com receptividade e assentimento ou com aversão, como no caso daqueles atores que não podem lidar mesmo com pequenos rompimentos da rotina. O acaso talvez seja o modo de interação que menos tinha sido abordado pela semiótica até Landowski (2014) e vemos que nisso consiste um tanto da importância atual de sua teoria, conjuntamente aos avanços obtidos com o estudo do ajustamento.

Da perspectiva de um estudo do protagonismo juvenil, o ajustamento é interessante, pois a aproximação estésica entre actantes pode ser usada para descrever processos de interação relacionais na subjetivação. Isso ocorre, por exemplo, em situações nas quais um ator se vê influenciado por outro e/ou influenciando-o na determinação dos planejamentos práxicos que irão guiá-los em suas atividades. Por sua vez, o regime do acidente - e as diversas maneiras de processá-lo subjetivamente - também possui funcionalidade própria no seio de nossa investigação, uma vez que está presente nos textos que reportam a esse processo de individuação. Greimas e Courtés (2012, p. 262, verb. "Individuação") definem este termo segundo a reunião de propriedades estruturais de ordem sintática e semântica junto à figura do ator de um texto.

Ressaltamos que a categoria continuidade - descontinuidade (e seus pares contraditórios, respectivamente, não continuidade e não descontinuidade) é essencial na proposta dos regimes de interação de Landowski, como bem ressalta Fiorin (In: LANDOWSKI, 2014). A ela associam-se quatro diferentes tipos de lógica, a da regularidade, a da sensibilidade, a da aleatoriedade e a da intencionalidade, que fazem com que seja possível que descrevamos semioticamente uma variedade de tipos de recção presentes nos textos. Para ilustrar essa associação, vejamos outro diagrama, no qual mostramos apenas a relação entre os regimes de interação e a categoria acima. 


\section{Programação Acidente \\ Continuidade \\ Descontinuidade}

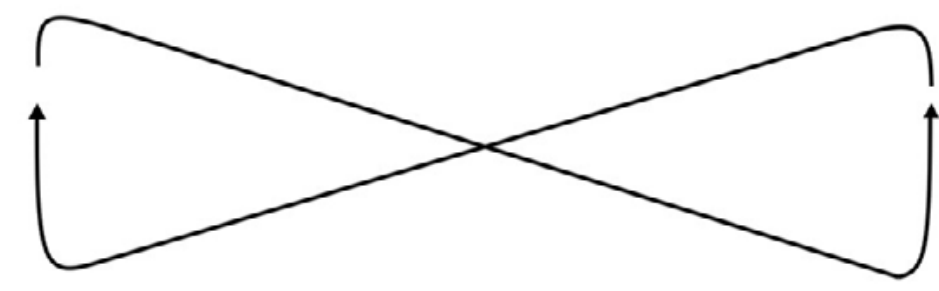

\section{Manipulação}

Não descontinuidade
Ajustamento Não continuidade

Figura 2. Diagrama dos regimes de interação e a categoria continuidade - descontinuidade

Fonte: Adaptação nossa, baseados em Landowski (2014, p. 80).

Se a teoria de Landowski (2014) está constituída a partir do par continuidade descontinuidade, convém lembrar que uma categoria similar a essa tem papel central nas bases da semiótica tensiva de Zilberberg, entre outras ocorrências ao longo da história da disciplina. Um dos primeiros textos que postularam a existência do dispositivo missivo, "Para introduzir o fazer missivo" (ZILBERBERG, 2006), ponto de partida para o desenvolvimento da ideia de acontecimento zilberberguiana, já trazia uma relação semelhante à do par acima, articulando-a com as noções de programa e antiprograma narrativos. Na ocasião, a formulação de um fazer emissivo foi levantada, tendo o ardor e o arroubo como valores. Já o fazer remissivo, por sua vez, segunda possibilidade postulada, seria responsável pela inibição, parada ou stase.

O modelo proposto por Zilberberg (2006) é o precursor do esquema da tensão, proposta que foi posteriormente depurada por Tatit (2014). Essa sistematização vem sendo utilizada para corpus de natureza variada, demonstrando grande rentabilidade analítica. Para ela, a tensão é o "termo complexo que subsume um potencial mínimo e um potencial máximo de intensidade emocional" (TATIT, 2014, p. 378). Vejamos abaixo como o pesquisador brasileiro sistematiza essas ideias. 


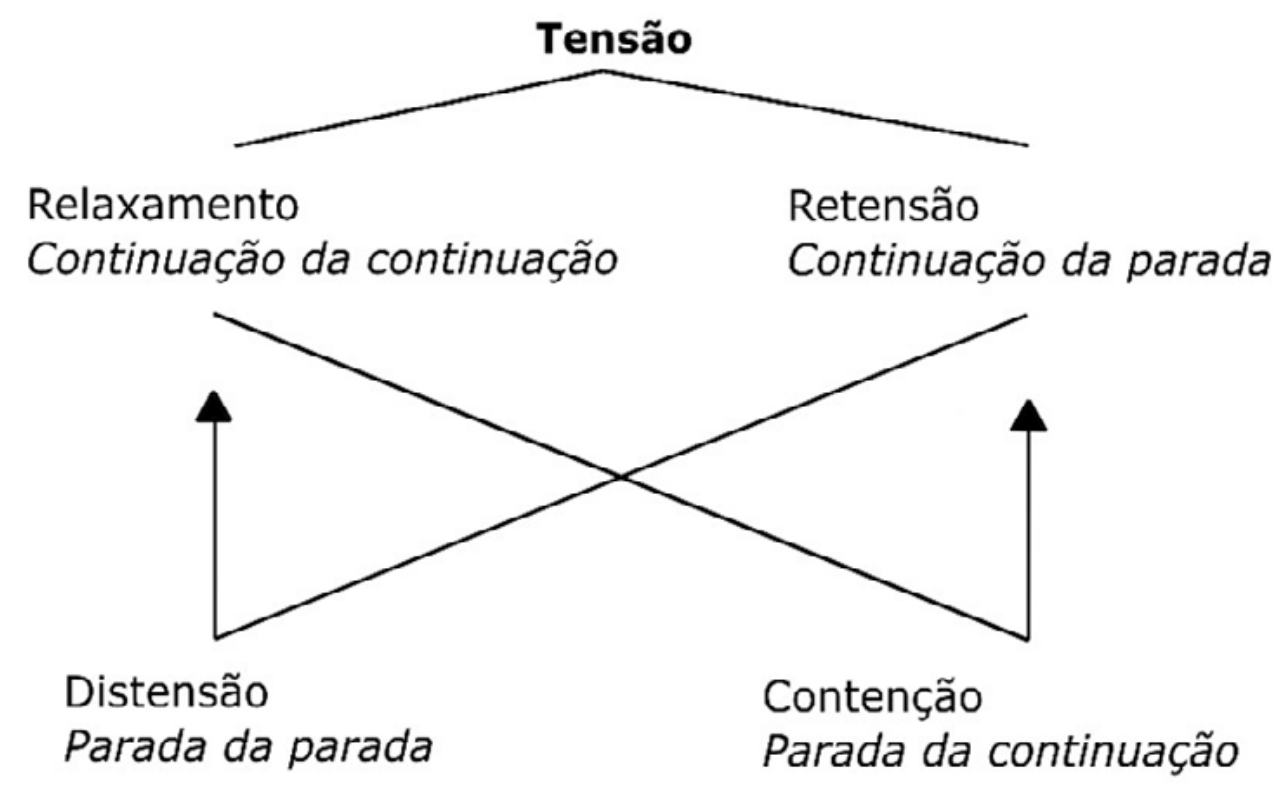

Figura 3. Diagrama tensivo

Fonte: Tatit (2014, p. 379). Reprodução nossa.

No que diz respeito à primeira das variáveis, o relaxamento, temos uma continuidade sem interrupções. Para Tatit (2014), esta seria correspondente à noção de progresso proppiana, assim como à ideia de "cotidianidade" presente em Da imperfeição (GREIMAS, 2002). O seu termo contrário, a retenção, por sua vez, preveria justamente uma descontinuidade efetivada. Ela asseguraria uma duração aos estados passionais, sendo também responsável pela apreensão estética (TATIT, 2014). A contenção (parada da continuação) seria uma formulação tensiva para a descontinuação ou a finalização e, por fim, a distensão (parada da parada), um sentimento de fratura que causaria o início dos processos narrativos. Estes dois últimos seriam elementos que estariam no eixo inferior, contradizendo cada um dos termos do eixo superior e estabelecendo uma relação de implicação quanto aos elementos superiores cruzados. O modelo tensivo vem sendo utilizado especialmente pela semiótica da canção, talvez por ser uma proposta bastante apta a descrever a nuance dos componentes melódicos e verbais - e sua interação - nas músicas com letra. Tal uso se vê exemplificado em diferentes obras de Tatit.

Tendo visto rapidamente como um dos pares elementares constituintes da significação (continuidade - descontinuidade) transita naqueles que hoje se denominam os campos de estudo da sociossemiótica e da semiótica tensiva, ressaltamos que ambas teorias partem de uma oposição similar para chegar a aplicações distintas. Nesse sentido, acreditamos que há diversos diálogos teóricos que podem ser percorridos almejando uma integração maior dos modelos. 


\subsection{Um breve olhar às problemáticas do encadeamento e valorização de programas narrativos, com base em Greimas e Tatit}

Como dito anteriormente, entendemos aqui a ideia de "ação" tal como concebida pela semiótica greimasiana standard, ou seja, um fazer narrativo investido por instâncias discursivas (GREIMAS; COURTÉS, 2012), podendo sua manifestação textual ocorrer por meio de gestos físicos, realizações verbais, entre outras possibilidades. A semiótica já dedicou alguma atenção ao assunto da gestualidade, ou a "utilização feita pelo homem de seu próprio corpo frente à produção de movimentos organizados em programas que tenham um projeto, um sentido comum" (GREIMAS, 1975, p. 64). No âmbito daquilo que consideramos como uma análise inicial da problemática das práticas na disciplina, ainda na obra citada, o autor lituano defenderia que o projeto do programa gestual corresponderia ao significado da semiose gesticular, ao passo que a sequência de ações que recobririam esse projeto seria o seu significante. Mais adiante, Greimas e Courtés (2012, p. 380) diriam que as "práticas semióticas" são "processos semióticos reconhecíveis no interior do mundo natural" e que elas poderiam ser definidas "de modo comparável aos discursos".

Tatit (2010) no capítulo "Práticas impregnantes 'A terceira margem do rio"' analisa um conto de Guimarães Rosa, tomando como base a obra do professor lituano e de seus discípulos. Em dado momento da obra, aborda a problemática das práticas semióticas e, em suas reflexões, faz menção a uma possível tipologia elementar para elas. Em primeiro lugar, vale lembrar que a argumentação do brasileiro considera que, em uma realização fonológica como a da inserção do fonema /e/ na sequência silábica mais extensa "europeu", o "projeto semântico mais abrangente de uma cadeia depende da dessemantização de eventuais sentidos associados a segmentos fonológicos de menor dimensão" (TATIT, 2010, p. 110, grifos nossos). Dessa maneira, recupera o conceito em itálico, anteriormente mencionado por Greimas (1975). Este se veria expresso, sobretudo, na prática utilitária, pela sua tendência para "a dessemantização das figuras parciais em nome da valorização do projeto geral" (TATIT, 2010, p. 111). É importante ressaltar também que as análises desenvolvidas pelo autor brasileiro na obra mencionada são feitas desde uma perspectiva tensiva, que atribui novas nuances interpretativas à abordagem de Greimas.

Tatit (2010) analisa a prática do personagem paterno rosiano que embarca numa canoa sem aparentes razões. O semioticista depreende, a partir da análise das ações dos atores discursivos presentes no texto, diferentes mecanismos de atribuição de sentido, chegando a distinguir o que seriam práticas utilitárias, artísticas, desvairadas e impregnantes. Para tanto, explora diferentes formas de relação entre o que seriam os PN's de uso e o de base na narrativa. 
Muito embora já tivesse sido trabalhada por Greimas (1975) anteriormente, a ideia de prática mítica não é muito explorada no texto do autor brasileiro, sendo mencionada apenas uma vez na obra aqui citada (TATIT, 2010). Talvez isso se deva ao desenvolvimento da proposta recente. Esta poderia tê-la incorporado em meio à concepção do que seriam as práticas artísticas (que valorizariam os percursos parciais e os manteriam em sintonia com os projetos mais amplos). Por outro lado, o próprio Tatit (2010, p. 122, grifos nossos) menciona que a figura do pai canoeiro, ao desempenhar sua ação inesperada e duradoura, adquiriria uma "estatura de mito, e, portanto, de representante de uma outra esfera de valores", o que mostra que, de alguma maneira, a ideia de um significado mítico das práticas não tinha sido, afınal, absolutamente deixada de lado por ele. A ideia de prática desvairada, em Tatit (2010), teria como característica principal a desvalorização do programa de base em função daquele de uso. Nesta última, o PN local conservaria sua autonomia semântica em detrimento do sentido mais amplo.

Em Sobre o sentido, Greimas (1975) dedicava alguma atenção à diferenciação de dois regimes básicos de atribuição de sentido das figuras gestuais, a saber, o prático e o mítico. O primeiro deles era considerado basicamente relacionado ao fazer. O segundo estaria relacionado ao ato de desejar. Este último, aparentemente, supunha uma significação conotativa, muito embora não pudesse estar limitado apenas a ela, pois, segundo o próprio autor, ele estaria também permeado pela ideia, mais ampla, de "uma intencionalidade transformadora do mundo como tal" (GREIMAS, 1975, p. 65, grifos do autor). Voltando a Tatit (2010), a prática impregnante, por sua vez, é identificada por ele como sendo a que melhor descreveria o fazer do pai canoeiro, associada ao que aponta como um acontecimento extenso. Segundo ele, estaríamos aí diante de "atos que se somam no campo de percepção do sujeito comprometendo sua capacidade de dar respostas parciais a cada um deles" (TATIT, 2010, p. 117), ou ainda de "um acontecimento que não se consuma, mas que [...] consome o mundo subjetivo" (TATIT, 2010, p. 117).

\section{Conclusões parciais: por um olhar semiótico à metodologia do protagonismo juvenil}

No âmbito de um diálogo entre a semiótica francesa e a metodologia do protagonismo juvenil, a problemática das práticas desempenha um papel importante. Essa ação educativa, em linhas gerais, visa o desenvolvimento de uma capacidade de autonomia, a partir do envolvimento e da participação dos educandos em atividades variadas (COSTA, 2000). Vemos que os processos de planejamento variados, elaborados pelos jovens no que concerne à determinação de suas ações em esferas variadas de suas vidas (participação na família, na escola, na sociedade etc.) estão pautados por interações de ordem semiótica. Um conhecimento maior a respeito das construções subjacentes a essas relações pode, a nosso ver, contribuir, para a elaboração de melhores propostas formativas por parte dos educadores e formadores que trabalham com jovens. 
As formas de articulação entre os programas narrativos de uso e de base, na semiótica, têm sido utilizadas para a análise das diferentes dinâmicas existentes no processo estratégico de organização do percurso narrativo, instância mais abrangente do que elas. A organização de práticas mais amplas a partir de PNs de menor alcance se dá pelo mesmo mecanismo essencial da capacidade linguageira humana que atribui sentido aos diferentes processos semióticos reconhecíveis no mundo natural. Nesse sentido, são as reflexões examinadas no item 2.3, extraídas das reflexões de Greimas (1975), Greimas e Courtés (2012) e Tatit (2010), que recuperam esse vínculo.

Além disso, a hipótese central com a que estamos trabalhando em nossa tese de doutorado (em meio à qual desenvolvemos este artigo) é a de que há uma forma elementar de estabelecimento de contrato narrativo pautada por uma instância factitiva que seria "interna" ao ator do sujeito. Postulamos que o "jovem protagonista" seria aquele que, tanto quanto possível, fosse constituído como um indivíduo "automotivado" no processo autobiográfico de discursivização de sua vida. Tal manifestação, em nosso caso, encontra-se nas entrevistas coletadas por nós para a pesquisa. Haveria, no tipo de relação expresso acima, a presença de uma única figura actorial que investiria os papéis actanciais de destinador-manipulador, destinatário-manipulado e sujeito. Outra forma igualmente válida de designarmos o fenômeno seria chamá-lo de contrato reflexivo, denominação que remeteria a esse relacionamento de natureza fiduciária, estabelecido entre os actantes acima mencionados, quando investidos por um mesmo ator. Contudo, no atual momento da pesquisa, ainda não foi possível encontrar elementos que permitam afirmar a presença de um "protagonismo pleno" nesses termos, a partir do corpus estudado.

De modo geral, nos relatos observados, os jovens declaram ser motivados por instâncias interdiscursivas variadas e, assim, torna-se difícil atestar, de forma inequívoca, o vínculo de seus valores com um aparato decisório próprio. Por outro lado, vemos que é igualmente proveitoso nas análises nos perguntar quais são as forças que atuam na composição estratégica da determinação dos percursos de vida nesses discursos autobiográficos e verificar, segundo diferentes categorias descritivas, as formas como elas atuam. Para tanto, valemo-nos da distinção de Landowski (2014), que prevê uma forma de manipulação que se apropria e confere significado a um percurso prático do sujeito a partir de uma lógica decisional, assim como outra, que determina uma forma de motivação interna e de natureza fiduciária, como a motivação-confiança. Indo além desses dois princípios, a teoria postulada tem se mostrado útil na análise de outros aspectos dos discursos observados por nós. Acreditamos que esse aparato teórico consiste em uma boa ferramenta de apoio para a elaboração de metodologias educacionais que visem desenvolver uma participação maior dos jovens nas suas comunidades, assim como nos diferentes âmbitos sociais nos quais atuam. 
A abordagem de Fontanille (2008), no que diz respeito aos capítulos iniciais da obra citada, é mais dirigida à problemática da integração das práticas envolvidas nos textos, focando menos nos mecanismos motivacionais, nos modos de interação e naquilo que diz respeito aos processos de planejamento práxico do sujeito. Assim, consideramos essa parte da proposta não tão pertinente para as questões aqui levantadas. Por outro lado, as ideias contidas nos capítulos V e VI da mesma obra (FONTANILLE, 2008) trazem considerações muito próximas da problemática que estamos tratando. Tomemos, por exemplo, a postulação de que haveria uma variedade de modos de ligação depreendidos entre actante operador e ato, expressa, na ocasião, sob o conceito de inerência, ideia especialmente interessante nesse sentido. Com certeza, as suas reflexões que problematizam elementos oriundos do universo da filosofia e da retórica diante das ideias semióticas merecem maior atenção por parte de estudos futuros, visando explorar o papel que as construções discursivas têm na determinação qualitativa das ações individuais.

A título de conclusão, atestamos aqui a pertinência da utilização dos conhecimentos desenvolvidos pelo estudo das práticas semióticas na análise dos discursos orais autobiográficos. Igualmente consideramos que cada uma das propostas teóricas examinadas traz contribuições autênticas e úteis para a problematização da metodologia educativa do protagonismo juvenil.

\section{REFERÊNCIAS}

BAILLY, A. Dictionnaire Grec-Français. Paris: Hachette, 1935. Disponível em: https://archive. org/details/BaillyDictionnaireGrecFrancais. Acesso em: 01 jul. 2018.

COSTA, A. C. G. da. Juventude popular urbana: educação, cultura, trabalho: a parceria entre ONGs de base comunitária e empresas: o case ACJ Brasil United-Way. São Paulo: Associação Caminhando Juntos - ACJ, 2007.

COSTA, A. C. G. da. Protagonismo juvenil: adolescência, educação e participação democrática. Salvador: Fundação Odebrecht, 2000.

DELORS, J. et al. Educação, um tesouro a descobrir: relatório para a UNESCO da Comissão Internacional sobre educação para o século XXI. Brasília: Setor de Educação da Rep. da Unesco no Brasil, Fund. Faber-Castell, 2010. Tradução G. J. de Freitas Teixeira. Disponível em: http://unesdoc.unesco.org/images/0010/001095/109590por.pdf. Acesso em: 28 jan. 2018.

FONTANILLE, J. Pratiques sémiotiques. Paris: Presses Universitaires de France, 2008. 
LANDOWSKI, E. Interações arriscadas. Tradução L. H. O. da Silva. São Paulo: Estação das Letras e Cores: Centro de Pesquisas Sociossemióticas, 2014.

GREIMAS, A. J. Sobre o sentido II: ensaios semióticos. Tradução D. Ferreira da Cruz. São Paulo: Nankin: Edusp, 2014.

GREIMAS, A. J. Da imperfeição. Tradução A. C. de Oliveira. São Paulo: Hacker Editores, 2002.

GREIMAS, A. J. Sobre o sentido: ensaios semióticos. Tradução A. C. Cruz Cesar et al. Petrópolis: Vozes, 1975.

GREIMAS, A. J.; COURTÉS, J Dicionário de semiótica. 2. ed. 1. reimp. Tradução A. Dias Lima et al. São Paulo: Contexto, 2012.

HOUAISS, A.; VILLAR, M. de S. Grande Dicionário Houaiss da Língua Portuguesa. 2. reimp. Rio de Janeiro: Secretaria de Cultura do Rio de Janeiro, Objetiva, 2007.

PORTELA, J. C.; SCHWARTZMANN, M. N. A noção de gênero em semiótica. In: PORTELA, J. C. et al. (org.). Semiótica: identidade e diálogos. São Paulo: Cultura Acadêmica, 2012. p. 69-95.

PORTELA, J. C. et al. (org.). Semiótica: identidade e diálogos. São Paulo: Cultura Acadêmica, 2012. p. 69-95.

TATIT, L. Semiótica à luz de Guimarães Rosa. São Paulo: Ateliê Editorial, 2010.

TATIT, L Todos entoam: ensaios, conversas e lembranças. 2. ed. Cotia: Ateliê Editorial, 2014.

ZILBERBERG, C. Razão e poética do sentido. Tradução I. C. Lopes; L. Tatit e W. Beividas. São Paulo: Editora da Universidade de São Paulo, 2006. 